\title{
SOCIAL FACILITATION OF SELECTIVE MORTALITY
}

\author{
Mark I. McCormick ${ }^{1,3}$ and Mark G. Meekan ${ }^{2}$ \\ ${ }^{1}$ School of Marine and Tropical Biology, James Cook University, Townsville, Queensland 4811 Australia \\ ${ }^{2}$ Australian Institute of Marine Science, P.O. Box 40197, Casuarina MC, Northern Territory 0811 Australia
}

\begin{abstract}
Territorial defense by breeders influences access to resources near defended nest sites by intruder species and may have indirect effects on other species within the territory, leading to local patchiness in distribution patterns. The present study demonstrates that adult males of a damselfish, Pomacentrus amboinensis, indirectly facilitate the increased survival of conspecific juveniles through the territorial defense of their nesting site from potential egg predators. Moreover, male territoriality results in a shift in the selectivity of predation on newly settled juveniles. We monitored the fate of pairs of predator-naïve, newly settled $P$. amboinensis placed inside and outside nesting territories. Individuals within a pair differed in size by $\sim 1 \mathrm{~mm}$ and were tagged for individual identification. Away from male territories larger juveniles had greater survival, while within territories, larger juveniles suffered higher mortality. Behavioral observations indicated that the moonwrasse Thalassoma lunare, a predator of benthic eggs and small fishes, had reduced access to juveniles within male territories, while another predator on small fishes, the dottyback Pseudochromis fuscus, had unobstructed access to male territories. Experimental removal of $P$. fuscus indicated that the shift in the direction of phenotypic selection on newly settled juveniles was the indirect effect of aggression by nest-guarding male damselfish, which resulted in differential access to male territories by these two predators of small fishes. Evidence suggests that behavioral interactions between the resident community and intruders will influence patchiness in selective pressures imposed on benthic prey by influencing both the composition of predator types that can access the prey resource and their relative abundance. How this spatial and temporal patchiness in predator pressure interacts with spatial patchiness of recruiting prey will have a major influence on the resulting distribution of juveniles and their phenotypic traits.
\end{abstract}

Key words: behavior; coral reef fish; density-mediated indirect effects; phenotypic selection; predator interference; predator-prey; selective mortality; settlement; size-selection; territoriality.

\section{INTRODUCTION}

Patchiness of populations within a habitat can be produced by the aggregation of similar organisms driven by social dynamics or through differential survival in space. Attraction to conspecifics, or similar looking organisms, may also reinforce patterns established by differential mortality and result in the aggregation of young around adults (Moland et al. 2005). The formation of such groups may improve foraging efficiency, decrease time spent on vigilance, and improve growth and survival (Stachowicz 2001, Krause and Ruxton 2002, Boland 2003). The presence of adult residents may also influence juvenile growth and survival independent of the advantages of being in a group through such mechanisms as the modification of habitat or community composition. Social facilitation of growth and survival may have a major influence on juvenile distributions and survival of those organisms with dispersive life-history stages, such as many insects, aquatic invertebrates, and fishes (Menge 1995).

Manuscript received 18 May 2006; revised 3 September 2006; accepted 1 December 2006. Corresponding Editor: S. R. Thorrold.

${ }^{3}$ E-mail: mark.mccormick@jcu.edu.au
The attraction to conspecifics has obvious selective advantages for dispersed offspring, with the presence of an established population indicating that survival for younger stages is possible. For these organisms, the end of the larval stage and the beginning of the site-attached phase (i.e., settlement, for most marine organisms) represents a critical period, where mortality can be high and selective (Pechenik et al. 1998, Vonesh 2005). Typically, these newly settled juveniles are subject to exponential mortality schedules, with highest levels of mortality occurring on naïve individuals, often exceeding 30\% during the first day (Gosselin and Qian 1997, Almany and Webster 2006). Factors that have relatively minor effects on mortality levels during this newly settled period can accumulate to become major influences on the total number of individuals surviving to maturity. Likewise, processes that influence which individuals are selectively lost from the population can have a major influence on the subsequent distribution of phenotypic (Pechenik et al. 1998, Vigliola and Meekan 2002, Giménez 2004) and genotypic traits (Planes and Romans 2004, Jones and Barber 2005).

Coral reef fishes are an ideal group to study the influence of social interactions on settlement and subsequent survival because almost all have complex 
life histories that typically divorce adults from their surviving offspring through a dispersive larval phase. Mortality after settlement is often at least $50 \%$ over the first 1-2 days (Doherty et al. 2004, Almany and Webster 2006). Moreover, predation immediately after settlement can be selective for various traits including body size (Carr and Hixon 1995, Sogard 1997, Vigliola and Meekan 2002, Brunton and Booth 2003, McCormick and Hoey 2004, Holmes and McCormick 2006), lipid content (Booth and Hixon 1999, Booth 2002a, Booth and Beretta 2004, Hoey and McCormick 2004), and larval growth history (Searcy and Sponaugle 2001, Vigliola and Meekan 2002, Hoey and McCormick 2004).

The extent of predation and whether or not it is selective depends on the selection profiles of gapelimited predators (Rice et al. 1997). In a species-rich coral reef system, the cumulative selection profile of the multispecies predator pool will have a major influence on the nature of selection (Paradis et al. 1996, Holmes and McCormick 2006). However, space within the shallow coral reef is not equally accessible to all species because much of the benthic habitat is occupied by small fishes with established territories that are aggressively defended (Sale 1975, Ceccarelli et al. 2001, 2005). Resources defended within these territories may include food, mates, or nest sites, with the resource type determining the nature and target of aggressive interactions (Ceccarelli et al. 2001). A patchwork of territories effectively results in differential access to parts of the reef by species, depending upon how they interact with resident territory holders. Mortality rates and phenotypic selection may mirror some of the patchiness in space use by these aggressive, key resource holders through their influence on the activity patterns of predators.

In the present study, we focus on a common IndoPacific damselfish, Pomacentrus amboinensis, whose breeding males aggressively defend benthic nest sites against potential egg predators, some of which are also predators on newly settled and juvenile fishes. Here, we test two predictions: (1) recently settled fish in male territories will have higher survival if fishes excluded from those territories are also predators on small fishes, and (2) phenotypic selection on recently settled fish may be different inside territories because small fish may be exposed to a different or restricted suite of predators displaying different prey-selection profiles. A combination of visual surveys, field experiments, and behavioral observations demonstrate that social facilitation may influence survival and the direction of selection by predators on newly settled fish.

\section{Methods \\ Study species and site}

The protogynous damselfish Pomacentrus amboinensis is common on coral reefs of the Indo-Pacific. Males guard a benthic nest and have between one and seven associated females that live in a linear dominance hierarchy based upon relative body size (M. I. McCormick, unpublished data). Males and females are strongly site attached and often live in a discrete group. Males guard their nest sites during the breeding season (October to January on the northern Great Barrier Reef) and are aggressive to egg predators that come within a 1$1.5 \mathrm{~m}$ radius of the nest (M. I. McCormick and M. G. Meekan, personal observations). In the present study, natural male nests were removed and replaced by artificial nest sites (a plastic half tile $30 \mathrm{~cm}$ long, $18 \mathrm{~cm}$ in diameter) to standardize nest size and defensibility. Previous studies have shown that adults readily adopt, spawn on, and guard these nests (McCormick 2006). Outside the breeding season, males are strongly site attached but do not overtly defend areas from interspecific intrusion. During the main breeding season, some breeding males have a hiatus in nest guarding around the new moon (for up to a week), while most will continue to defend benthic nests (M. I. McCormick, personal observation). In the present study, nesting fish guarded their nest over the whole study period, while some males that did not guard nests at the beginning of the study started guarding nests by the end. $P$. amboinensis has a pelagic larval duration of 15-23 d and settles at 10.3-15.1 mm standard length (Kerrigan 1996) with its juvenile body plan largely complete (McCormick et al. 2002). Although $P$. amboinensis settle to a wide variety of habitats on reefs of the northern Great Barrier Reef, they are found in highest densities associated with mixed rubble and sand areas on the shallow reef base or reef slope. A tagging study of 295 newly settled fish found that fish moved little over the first three months after settlement (mean $=0.63 \mathrm{~m}$; McCormick and Makey 1997; see also Booth 2002b). The present study was conducted on small patches of coral rubble $(15 \times 15 \times 15$ $\mathrm{cm})$ positioned amongst the rubble and sand at the base of a shallow reef at Lizard Island $\left(14^{\circ} 38^{\prime} \mathrm{S}, 145^{\circ} 28^{\prime} \mathrm{E}\right)$, northern Great Barrier Reef, Australia, during November 2005 to January 2006.

Newly settled reef fishes tend to be site attached and are subject to an array of resident and transient predators. The most common predators at the Lizard Island study site were the moonwrasse (Thalassoma lunare), the dottyback (Pseudochromis fuscus), and two species of lizardfishes (Synodus variegatus and $S$. dermatogenys; Martin 1994, Beukers and Jones 1997, Holmes and McCormick 2006). P. fuscus is a resident, site-attached predator (Michael 2004), while the other four common predators have broader home ranges (M. I. McCormick and M. G. Meekan, personal observations). All predators can be seen striking at and occasionally capturing recently settled and juvenile reef fishes during the summer recruitment period.

\section{Conspecific densities near nest sites}

The densities of all fish species were counted within a cylindrical sampling unit of $1 \mathrm{~m}$ radius. Counts were 
done in pairs, with one count centered on the guarded nest of a male Pomacentrus amboinensis. The second count in each pair was undertaken in an adjacent section of reef that did not contain the territory of a breeding male, and which was far enough away to not be influenced by the fishes within the nest-centered count ( 3-4 $\mathrm{m}$ apart). Eighteen nest and non-nest sites were surveyed. Pairing counts reduced variability in the densities of small fish due to small scale differences in habitat and replenishment history. P. amboinensis were placed into the following categories: recent recruits (within the last week, 10.3-15.1 mm standard length [SL]), juveniles from the previous lunar pulse (15.2-25 $\mathrm{mm}$ SL, although most were 20-25 mm SL), and fish that were estimated to have settled more than one month previously ( $>25 \mathrm{~mm} \mathrm{SL})$. Goodness-of-fit tests were used to determine whether juveniles from the two latter age groups displayed a similar trend to the relative abundance of recent recruits between guarded nest areas and the adjacent reef (i.e., we tested whether they conformed to the density ratio of 2.22 , which was found for recent recruits near a nest site for every one fish in adjacent areas). This analysis was used to suggest whether the initial differences in recruit density between nest and adjacent areas were maintained, lost, or accentuated with time. To enable analyses, densities were standardized to per $30 \mathrm{~m}^{2}$ and a Yates correction was employed.

\section{Predator densities}

The abundance of known predators of small reef fishes was estimated in the vicinity of $\sim 18$ nest sites and 18 adjacent non-nest areas in conjunction with the Pomacentrus amboinensis surveys. Two main predators, the moonwrasse Thalassoma lunare and the dottyback Pseudochromis fuscus, were the focus of these counts. Other predators, such as various rock cods and wrasses, were also recorded, but their low densities and cryptic habits prevented realistic estimation of their abundance. Densities of the two main predators were tested between nest and non-nest sites using Wilcoxon matched-pairs tests, since intractable heterogeneity of variance between treatments prohibited the use of parametric statistics.

\section{Habitat assessment}

Habitat was quantified to determine if there were differences in microhabitat characteristics between nesting and non-nesting sites that may explain differences in fish density. Percentage cover of 16 habitat categories within a $1 \mathrm{~m}$ radius of a $P$. amboinensis nest site and adjacent non-nest areas (censused above) was visually assessed. Categories were chosen to include all growth forms: 10 hard coral groups (Acropora, staghorn or bushy; Acropora, dead but standing; Porites, finger or massive; Pocillopora damicornis, live or dead but standing; other branching, live; other massive, live; encrusting, live; other, dead but standing); soft coral; sponge; turfing algae; sand; sand and rubble ( $\sim 50 \%$ each); coarse rubble (mean size $>10 \mathrm{~cm}$ ); fine rubble (mean size $\leq 10 \mathrm{~cm}$ ). Percent cover was estimated visually within the $1 \mathrm{~m}$ radius sampling area by one observer (M. I. McCormick). Such estimates have been shown to provide repeatable and accurate estimates of cover for benthic substrata (McCormick 1990). Substrata were compared between 18 nesting and 18 nonnesting sites using nonparametric multivariate analysis of variance (NPMANOVA; Anderson 2001) due to the unequal variance structure and non-normality of the data. For this analysis, data were grouped into five variables (massive and encrusting corals, branching and bushy corals, coarse rubble and dead standing coral, fine rubble, sand and rubble). A Bray-Curtis matrix was used and 5000 permutations were undertaken.

\section{Experimental protocol}

Light traps were used to collect Pomacentrus amboinensis at the end of their larval phase. Traps (for design, see Meekan et al. 2001: Fig. 1) were moored close to the reef crest overnight and catches brought back to the Lizard Island Research Station at dawn. Fish were placed into an aquarium with aerated flowing seawater (density $\sim 50$ per $40 \mathrm{~L}$ ). Fish were kept for $30 \mathrm{~h}$ and fed newly hatched Artemia sp. twice per day ad libitum, to allow recovery from (or acclimation to) the stress of capture, prior to tagging. There was no mortality during this time and growth was minimal. Individual $P$. amboinensis were then placed into plastic zip bags containing aerated seawater and measured with calipers $( \pm 0.1 \mathrm{~mm})$. Fish were paired, such that one individual ("large" individual) was $0.8-1.0 \mathrm{~mm}$ larger in standard length than the other ("small") individual. To enable individual identification, fish were tagged through the plastic bag with either a red or blue subcutaneous fluorescent elastomer tattoo (Northwest Marine Technology, Shaw Island, Washington, USA) using a 29gauge hypodermic needle (as per Hoey and McCormick 2006). This left a 1.5-2 mm long stripe of color, which was visible under the fish's scales. Colors were alternated between large and small fish among replicates to avoid the possible bias of predators selecting prey based on tag color. Previous studies have found no evidence of this selection (T. Holmes, unpublished data).

Size-paired fish were transported to the study site in 8$\mathrm{L}$ plastic bags of aerated seawater and then released onto small patches of rubble $(15 \times 15 \times 15 \mathrm{~cm})$ placed either within $20 \mathrm{~cm}$ of a male $P$. amboinensis nest or on a similar sized patch in the vicinity of a non-nesting male. Each labeled patch consisted of a combination of live and dead Pocillopora damicornis. A small wire cage $(\sim 30$ $\times 30 \times 30 \mathrm{~cm}, 12-\mathrm{mm}$ mesh size $)$ was placed over the patch to allow the tagged fish to acclimate to their new surroundings while being protected from predators. We observed no size-dependent aggression between any of the pairs. Cages were removed $1-3 \mathrm{~h}$ after release of the fish between 14:00 and 17:00 hours (dusk at 18:45 
FIG. 1. Densities of recently settled Pomacentrus amboinensis near (open bars) and away from (gray bars) male $P$. amboinensis nest sites. Size categories were recent recruits (settling within the last week, $10.3-15.1 \mathrm{~mm}$ standard length [SL]), juveniles that settled from the previous lunar pulse $(15.2-25 \mathrm{~mm} \mathrm{SL}$, although most were 20-25 $\mathrm{mm} \mathrm{SL}$ ), and fish that were estimated to have settled more than one month previously $(>25 \mathrm{~mm} \mathrm{SL})$. Densities were determined using $1 \mathrm{~m}$ radius cylinder counts. Error bars are $95 \%$ confidence limits $(n=18)$.

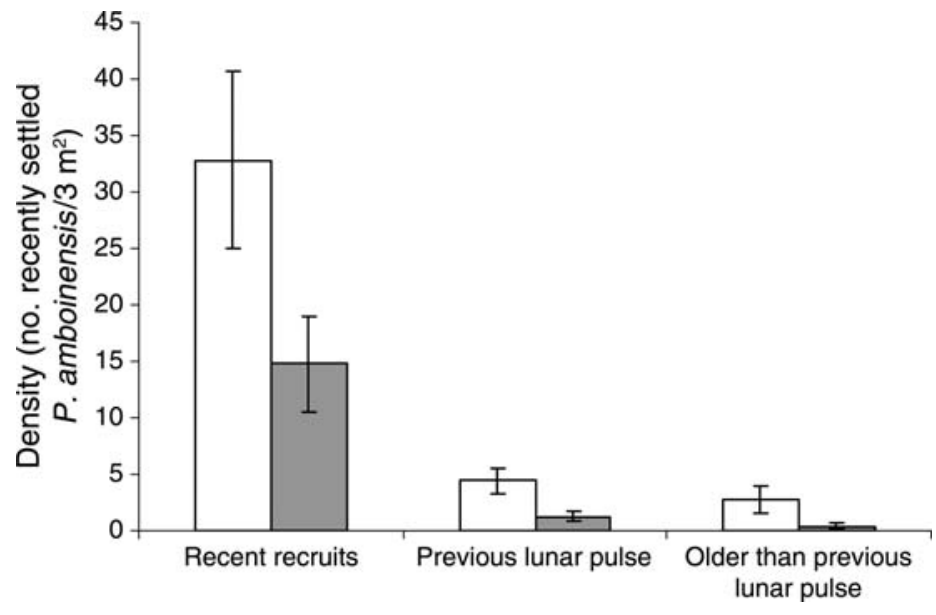

Behavior

The nest guarding behavior of male P. amboinensis was quantified to assess which intruder species were actively targeted by males and hence identify intruder species whose presence was likely to be less within territories. A range of species that were likely to be competitors for resources, egg predators, or predators on recently settled $P$. amboinensis were placed into 81 plastic bags and placed one at a time within $5 \mathrm{~cm}$ of the male's nest. Behavior of the resident male was recorded in categories over a 5-min focal sampling period. Three behavioral responses to intruders were recorded: displaying (showing side to target and erecting dorsal and anal fins), charging (or chasing species outside the bag), and biting. To maintain independence of trials, nesting males were not used in more than one trial within a 3-h period, and the order of intruder species to which males were exposed was randomized. Moreover, individual nesting males were not exposed to the same intruder species more than once. A total of 33 males had bagged fish placed near their nests. The males that were exposed to each of the intruders were a random subsample of these 33 focal fish (apart for $P$. amboinensis females, where the behavior of all males was tested; see Fig. 4 for sample sizes). Total aggressive interactions by nesting males to the bagged intruders were calculated as the sum of the three behaviors and differences among intruder species were tested using a Kruskal-Wallis test followed by multiple comparisons of mean ranks.

\section{Predator manipulation}

To determine if predation on recruits by the dottyback Pseudochromis fuscus led to size-selective mortality near male nests, these predators were removed from around five nest sites guarded by Pomacentrus amboinensis males. $P$. amboinensis collected by light traps were paired so that they were $0.8-1.0 \mathrm{~mm}$ different in size, tagged, and then placed on small patch reefs near these males (using the same methodology as previously described). For comparison, tagged pairs were also pair. 


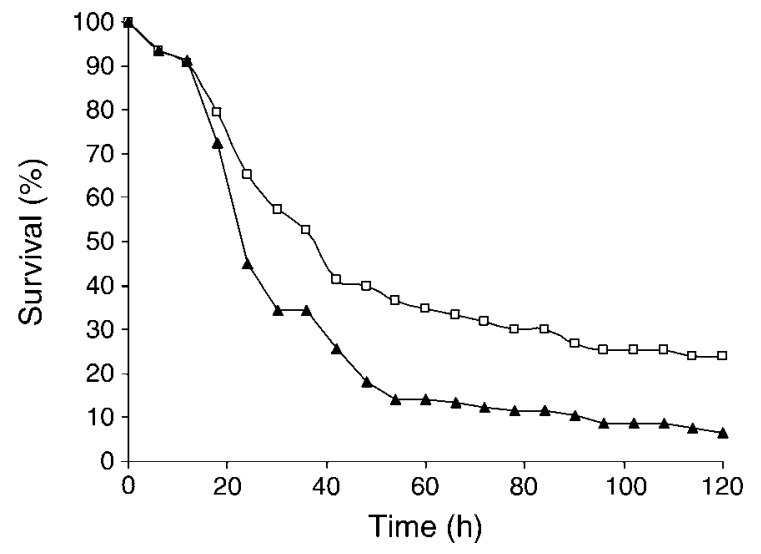

FIG. 2. Survival trajectories of recently settled Pomacentrus amboinensis placed near (open squares, $n=63$ trials) and away from (solid triangles, $n=105$ trials) male $P$. amboinensis nest sites.

placed on small patch reefs near nest-guarding males who had resident $P$. fuscus within their territories (trials were conducted using nine nesting males over a 2.5 -week period). The protocol for these size-paired trials was the same as detailed above, except due to time restrictions, trials were terminated when one of the tagged pair went missing. The effectiveness of the P. fuscus removals was assessed by 3 -min stationary counts centered on the patch reefs where fish were released. These were conducted at each census period ( $2-3$ times per day, as previously described). Goodness-of-fit tests (with a Yate's correction) were used to test whether the large or small individuals died more often than expected near male nests where $P$. fuscus had been removed compared to non-removal nest sites.

\section{Results}

The densities of recently settled Pomacentrus amboinensis were 2.2 times greater within a $1 \mathrm{~m}$ radius of a male nest site than near a non-nesting male (Fig. 1). There were 3.5 times as many P. amboinensis that had settled from the last lunar pulse near male nest sites than in adjacent areas, but this did not significantly differ from the trend found for recent recruits $\left(\chi^{2}=2.18, \mathrm{df}=\right.$ $1, P=0.157)$. Density differences were amplified for juveniles from previous lunar pulses, with 6.6 times as many fish near male nest sites than adjacent non-nest areas, which was a significantly greater magnitude of difference between nest and non-nest areas than was found for recent recruits (Fig. $1 ; \chi^{2}=4.945, \mathrm{df}=1, P<$ $0.03)$.

The survival of newly settled $P$. amboinensis was higher near male nest sites than near adjacent nonnesting males (Fig. 2; Cox's $F_{100,180}=1.619, P<0.003$ ). After two days, $40 \%$ of the experimentally released individuals survived near male nest sites, while only $18 \%$ survived in adjacent non-nesting areas. After five days, survival near nests was approximately four times that of fish in adjacent non-nest areas (Fig. 2).

Habitat composition at nest and non-nest sites did not differ significantly $\left(F_{1,34}=0.171, P=0.918\right)$. On average, sand made up $60 \%$ of habitat, while rubble accounted for $20 \%$ of habitat. Coarse rubble or dead standing coral and bushy or branching corals accounted for $13.4 \%$ and $16.9 \%$ of habitat, respectively.

Fish were selectively lost from both near the male nest and in the adjacent habitat (Fig. 3). Small fish were selectively lost away from nesting males $\left(\chi^{2}=15.158\right.$, df $=1, P<0.0001$ ), while large fish were selectively lost from nest sites $\left(\chi^{2}=10.125, \mathrm{df}=1, P<0.001\right)$. There was a significant difference in the trends in selective loss between nest sites and adjacent patches (Fisher's exact test, $P<0.00001)$.

The behavioral reaction of nesting males to captive intruders differed among intruder species (Fig. 4; Kruskal-Wallis test: $H=110.205, \mathrm{df}=8, P<0.0001$ ). Males displayed the most aggression to conspecifics, competing planktivores, and the egg predator Thalassoma lunare. Males showed little aggression to the other three predators on recently settled fish ( $P$. fuscus, Epibulus insidiator, and Synodus variegatus), recruitstage conspecifics, or the control (empty bag).

The density of the Pseudochromis fuscus in the vicinity of male nest sites was higher than in adjacent non-nest sites $(Z=2.803, n=18, P=0.005)$. In 16 out of the 18 nest sites assessed, there was at least one P. fuscus, while this was the case for only 9 of 18 non-nest sites. The reverse trend was displayed by Thalassoma lunare, which had higher densities at non-nest sites (mean 1.33 fish per $3 \mathrm{~m}^{2}$ ) compared to near male nest sites (mean 0.21 fish per $3 \mathrm{~m}^{2} ; Z=3.059, n=18, P=0.002$ ).

When Pseudochromis fuscus was present near nest sites, the larger, newly settled Pomacentrus amboinensis in a tagged pair sustained significantly higher mortality (Fig. 5, $\chi^{2}=6.261, \mathrm{df}=1, P<0.01$ ). In contrast, when $P$. fuscus had been removed from the vicinity of nest

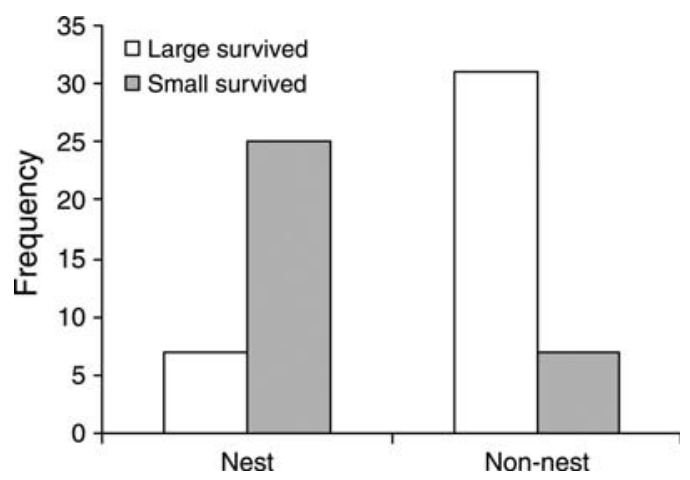

FIG. 3. Survivor counts of naïve, newly settled Pomacentrus amboinensis released in pairs $1 \mathrm{~mm}$ different in standard length near $(n=29$ trials) and away $(n=36$ trials) from male $P$. amboinensis nest sites. Frequency is the number of trials in which the larger individuals (white bars) or smaller individuals (gray bars) survived. 


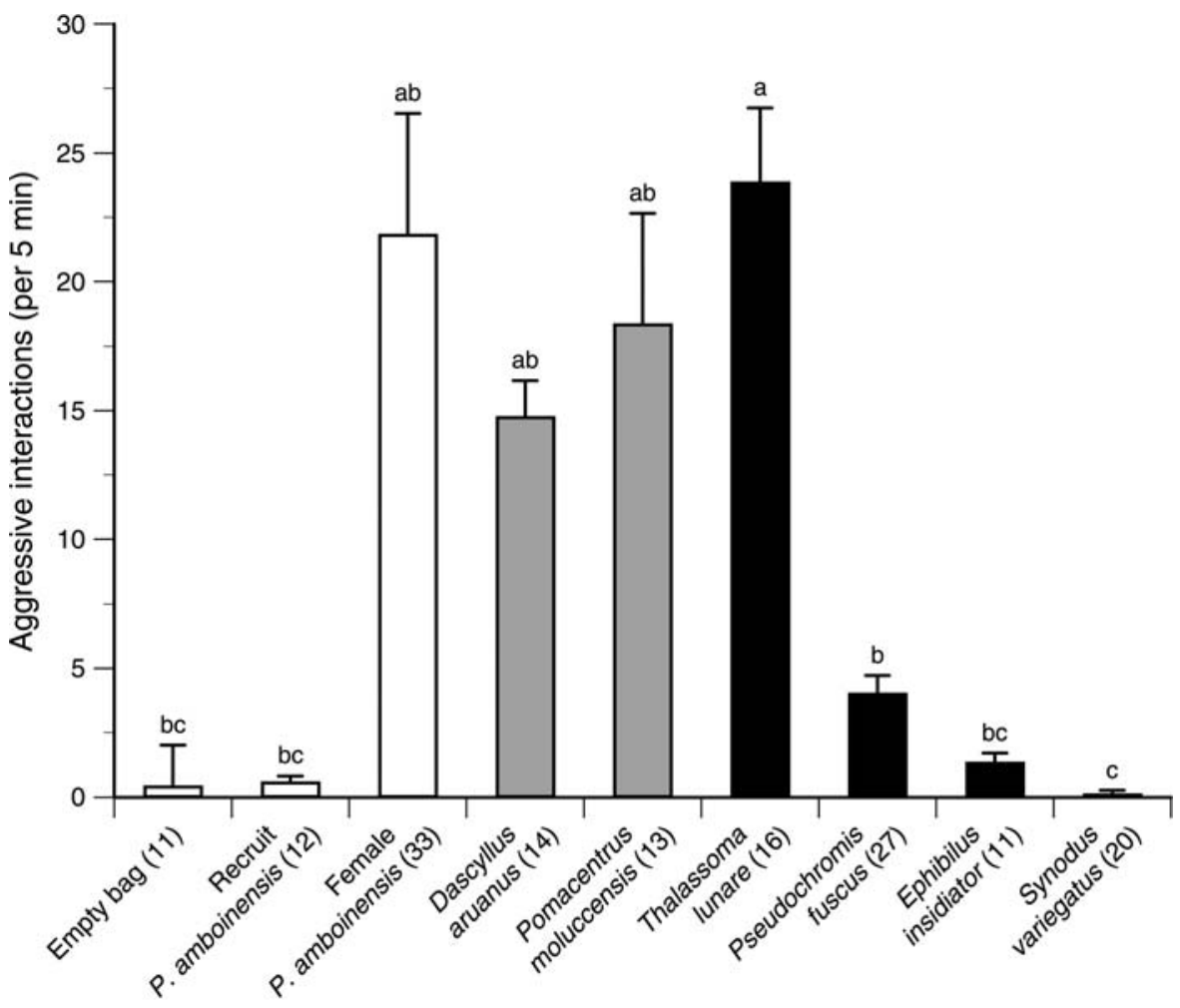

FIG. 4. Mean number of aggressive interactions of nest-guarding male Pomacentrus amboinensis within a 5-min period with an empty plastic bag (control), conspecific recruits, and females (open bars), two other species of cohabitating aggressive damselfishes that compete with $P$. amboinensis for food (gray bars), and four species of predators on recruit $P$. amboinensis (black bars). Intruder fishes were placed in 8-liter plastic bags and introduced one at a time to within $5 \mathrm{~cm}$ of the male's nest. Sample sizes (number of focal residents observed) are given in parentheses after the name of each intruder, and letters above bars represent groupings based on multiple comparisons of mean ranks. Error bars are standard errors.

sites, there was no difference in the levels of mortality sustained by large and small individuals (Fig. $5 ; \chi^{2}=0$, $\mathrm{df}=1, P=1)$.

\section{Discussion}

Settlement at the end of the larval stage is a dangerous transition for most coral reef fishes during which they sustain rates of mortality up to $100 \%$ within the first two days after settlement (Almany and Webster 2006). While survival probabilities increase rapidly after settlement, this early signature of intense mortality can persist to greatly influence the local distribution of individuals within a population (Booth 2002b, Webster and Almany 2002). Our study found that the presence of nestguarding territorial males greatly enhanced the survival of conspecific juveniles during this critical period immediately after settlement and that this effect persisted, leading to aggregations of juveniles in the vicinity of male nest sites. In this instance, males had a positive indirect effect on the survival of juvenile conspecifics. As a by-product of aggressively defending the nest site against egg predators, males also reduced the number of predators that could access juveniles within the territory. Specifically, they reduced access by the moonwrasse Thalassoma lunare, a common predator of small fishes (Beukers and Jones 1997). This indirect influence of adult behavior on the survival of the juveniles of the same species is a novel finding for fishes.

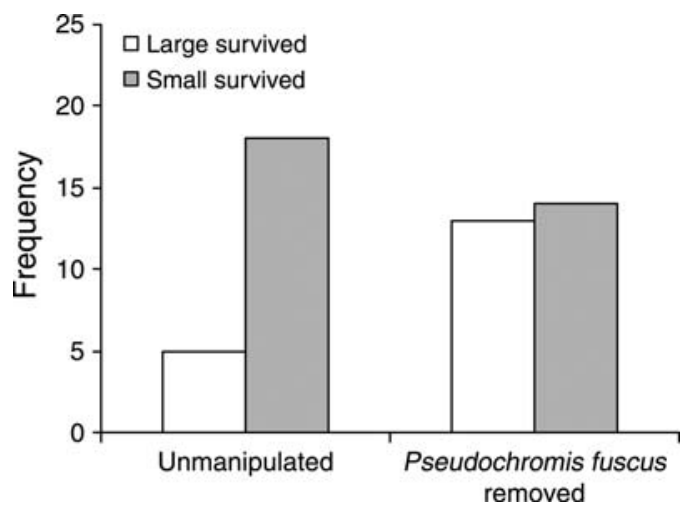

FIg. 5. Survivor counts of naïve, newly settled Pomacentrus amboinensis released in pairs $\sim 1 \mathrm{~mm}$ different in standard length near male $P$. amboinensis nest sites from which Pseudochromis fuscus had been removed ( $n=27$ trials) or not removed ( $n=23$ trials). Frequency is the number of trials in which the larger individuals (white bars) or smaller individuals (gray bars) survived. 
While the importance of indirect effects has been highlighted for plant-based terrestrial communities (Ohgushi 2005) and intertidal communities (Menge 1995), most coral reef studies have focused on the importance of direct effects on community dynamics. The present study is an example of a density-mediated indirect effect, where one species has an indirect effect on another species by altering the abundance of an intermediate species with which they both interact (Abrams et al. 1996, Schmitz 1998). Such effects are strongly correlated with direct effects; in this case the intensity of defense from egg predators that also prey on recruit fishes. This positive indirect effect of males on recruit survival is similar to that found by Webster and Almany (2002), who documented that the presence of large schools of cardinalfish on patch reefs greatly reduced the mortality sustained by other recently settled fishes. Similar indirect effects of territoriality have been shown on the diversity of algae (Hixon and Brostoff 1983) and the survival of microinvertebrates (Zeller 1988 ) within territories. These studies highlight the scope for indirect effects to influence the dynamics of fish communities on coral reefs.

The finding of enhanced survival of newly settled fish in the presence of adult damselfish contrasts with the findings of a number of other studies of tropical fishes (Shulman et al. 1983, Almany 2004). Almany (2004) used field experiments at Lizard Island to show that the presence of six species of resident damselfish increased the mortality of damselfishes within $48 \mathrm{~h}$ of settlement to patch reefs by $35 \%$. Many of these newly settled fishes were $P$. amboinensis, but there were also 11 other species included. The mechanism by which resident damselfish increased the mortality of new settled damselfish was unclear.

So why did the effect of resident damselfishes in the present study differ from those of previous studies? First, the present study was conducted on the contiguous reef edge, while Almany (2004) conducted experiments on isolated patch reefs. The behavioral dynamics of damselfishes may differ in the two habitats types. This would not be a unique finding, since a number of studies have shown differences in mortality rates between patch reef and contiguous reef habitats (Booth 2002b, Nanami and Nishihira 2003). Surprisingly however, both the present study and that of Almany (2004) found little evidence of aggression between residents and recently settled fishes, suggesting that residents may influence recently settled fishes indirectly. Second, the composition of the fish community was quite different between the two studies. Interspecific interactions may have had a major influence on the mortality rates of newly settled $P$. amboinensis. The present study and Webster and Almany (2002) demonstrate that the outcome of interspecific interactions among residents and piscivores can lead to indirect effects on the mortality schedules of recently settled fish, making predictions about the impacts of community differences on early survival difficult. Last, mortality schedules in the present study were recorded for newly settled fish within male territories, while mortality estimates in Almany (2004) were obtained without regard for the presence or location of damselfish territories. The present study indicates that relatively small differences in the location of settlement with respect to territorial individuals can greatly influence mortality rates.

The effect of territories on mortality of new settlers, and the mechanism by which it operates, will depend on the type of resources defended by the territory holder, which likely differ with species, gender, or size. Shulman (1985) demonstrated that herbivores can indirectly affect newly settled fishes by reducing algal refugia, which made new recruits more susceptible to predators. It is presently unclear whether nesting male $P$. amboinensis have a direct negative influence on the survival of newly settled conspecifics, but if they do, this negative influence appears to be outweighed by the male's positive indirect influence on survival by altering the predation regime within the territory.

The large number of similarly sized individuals accumulating around the male nesting territories may reduce per capita mortality of juveniles by reducing the efficiency of predators (predator swamping; Krause and Ruxton 2002). Advantages of being in a group have been well documented in schooling freshwater fishes (e.g., Godin 1986, Morgan and Colgan 1987), but the theory and literature focus on species that form tight schools rather than fishes like $P$. amboinensis, which form loose aggregations. It is unclear what advantages such loose groups may have on per capita survival rates, but even a small survival advantage may greatly influence the numbers reaching maturity.

Settlement facilitation (sensu Jones 1991) provides an alternative explanation to differential survival for the aggregation of juveniles around male nest sites. Some fish species settle into shoals of conspecifics or similar looking organisms, and this behavior is widespread amongst marine organisms (e.g., Alvarado et al. 2001, Kent et al. 2003, Lecchini et al. 2005). The best example is the humbug Dascylus aruanus which settles preferentially to patch reefs containing conspecifics (Sweatman 1983) using olfactory cues (Sweatman 1988). However, this does not appear to be an important mechanism promoting patchiness in $P$. amboinensis. A detailed experimental study of the settlement preferences of the species showed that although naïve settlers make strong microhabitat choices they do not show any preference for settling near conspecifics (Öhman et al. 1998).

Our study is the first demonstration that male territoriality can result in a shift in the direction of phenotypic selection by predators on newly settled fish. A larger size at settlement was advantageous away from male territories, while within the territory, being the largest in a group of settlers was disadvantageous. While bigger may be better when fish settled to areas open to all types of predators of juvenile fishes (e.g., Sogard 
1997, Brunton and Booth 2003, Hoey and McCormick 2004, McCormick and Hoey 2004, Holmes and McCormick 2006), the present study shows that phenotypic selection is altered when the suite of predators that can access the newly settled prey is modified by the presence and aggression of a resident territory holder.

The predator removal experiment suggests that the difference in the direction of size-selection between territory and non-territory areas was due to the differential access to the territory by the predators of small fishes. Removal of the predator Pseudochromis fuscus from territories resulted in a change in the direction of size selection from negative to random. This is in keeping with a recent experimental study which demonstrated that adult $P$. fuscus, regardless of their own size, consistently select the largest newly settled $P$. amboinensis (T. H. Holmes and M. I. McCormick, unpublished data). It appears that by directing aggression to egg predators in the defense of a nest site, the territorial male reduced predation pressure from $T$. lunare and in doing so enabled the signature of size selectivity from $P$. fuscus to be displayed. Data also suggest that $T$. lunare may be strongly negatively size-selective (i.e., selects smallest individuals), since this is the most common predator of settlement-sized fishes that was the primary recipient of aggression by nest-guarding males. Furthermore, the negative size selectivity away from male territories suggests that $T$. lunare must eat many more prey than $P$. fuscus to mask the selective signal of $P$. fuscus.

It is presently unclear how widespread the benefits of recruiting to a territory are for juvenile survival. On the reef we studied, $P$. amboinensis male nesting territories accounted for $\sim 5 \%$ of the narrow strip of rubble at the base of the reef where the species most commonly settles (M. I. McCormick, unpublished data). Other damselfish territories may afford similar survival advantages to recently settled fish, but this is currently unknown. Large, highly aggressive damselfishes, such as Dischistodus perspicillatus, also establish nesting territories in the same area, protect their territories from a similar array of egg predators, and these territories account for considerably more reef area (10-20\%, M. I. McCormick, unpublished data). Ceccarelli et al. (2005) found that territories of herbivorous damselfishes accounted for $60 \%$ of reef substrata down to $8 \mathrm{~m}$. Although not all the individuals with feeding territories will also use them as nest sites, these figures suggest that predators of small benthic fishes must run a gauntlet of territorial aggression to access this food source. The general repercussions of these findings are that any process that influences the access of key predators to their prey may influence not only the mortality trajectories of the prey but the frequency distributions of their life-history traits. The ramifications of the substantial reduction or removal of key predators through fishing on prey densities and lifehistory traits on coral reefs are yet to be addressed.
ACKNOWLEDGMENTS

We thank J. Moore, K. Winters, and G. Winstanley for their assistance in the field. We are grateful to G. Almany, P. Munday, M. Gagliano, and two anonymous reviewers for providing useful comments on the manuscript. The staff of the Lizard Island research station (a facility of the Australian Museum) provided logistic support. This project was funded through an Australian Research Council Centre of Excellence for Coral Reef Studies and was conducted as part of an AIMS@JCU joint venture. Research was conducted under the JCU animal ethics guidelines.

\section{Literature Cited}

Abrams, P. A., B. A. Menge, G. G. Mittelbach, D. A. Spiller, and P. Yodzis. 1996. The role of indirect effects in food webs. Pages 371-395 in G. A. Polis and K. O. Winemiller, editors. Food webs: integration of patterns and dynamics. Chapman and Hall, New York, New York, USA.

Almany, G. R. 2004. Priority effects in coral reef fish communities of the Great Barrier Reef. Ecology 85:28722880.

Almany, G. R., and M. S. Webster. 2006. The predation gauntlet: early post-settlement mortality in coral reef fishes. Coral Reefs 25:19-22.

Alvarado, J. L., R. Pinto, P. Marquet, C. Pacheco, R. Guinez, and J. C. Castilla. 2001. Patch recolonization by the tunicate Pyura praeputialis in the rocky intertidal of the Bay of Antofagasta, Chile: evidence for self-facilitation mechanisms. Marine Ecology Progress Series 224:93-101.

Anderson, M. J. 2001. A new method of non-parametric multivariate analysis of variance. Austral Ecology 26:32-46.

Beukers, J. S., and G. P. Jones. 1997. Habitat complexity modifies the impact of piscivores on a coral reef fish population. Oecologia 114:50-59.

Boland, C. R. J. 2003. An experimental test of predator detection rates using groups of free-living emus. Ethology 109:209-222.

Booth, D. J. 2002a. Larval supply, condition and persistence of the coral reef fish, Pomacentrus moluccensis. Proceedings Ninth International Coral Reefs Symposium 2:463-466.

Booth, D. J. 2002b. Distribution changes after settlement in six species of damselfish (Pomacentridae) in One Tree Island lagoon, Great Barrier Reef. Marine Ecology Progress Series 226:157-164.

Booth, D. J., and G. A. Beretta. 2004. Influence of recruit condition on food competition and predation risk in a coral reef fish. Oecologia 140:289-294.

Booth, D. J., and M. A. Hixon. 1999. Food ration and condition affect early survival of the coral reef damselfish, Stegastes partitus. Oecologia 121:364-368.

Brunton, B. J., and D. J. Booth. 2003. Density- and sizedependent mortality of a settling coral-reef damselfish (Pomacentrus moluccensis Bleeker). Oecologia 137:377-384.

Carr, M. H., and M. A. Hixon. 1995. Predation effects on early post-settlement survivorship of coral-reef fishes. Marine Ecology Progress Series 124:31-42.

Ceccarelli, D. M., G. P. Jones, and L. J. McCook. 2001. Territorial damselfishes as determinants of the structure of benthic communities on coral reefs. Oceanography and Marine Biology: an Annual Review 39:355-389.

Ceccarelli, D. M., G. P. Jones, and L. J. McCook. 2005. Effects of territorial damselfish on an algal-dominated coastal coral reef. Coral Reefs 24:606-620.

Doherty, P. J., V. Dufour, R. Galzin, M. A. Hixon, M. G. Meekan, and S. Planes. 2004. High mortality during settlement is a population bottleneck for a tropical surgeonfish. Ecology 85:2422-2428.

Giménez, L. 2004. Marine community ecology: importance of trait-mediated effects propagating through complex life cycles. Marine Ecology Progress Series 283:303-310. 
Godin, J.-G. 1986. Risk of predation and foraging behaviour in shoaling banded killifish (Fundulus diaphanus). Canadian Journal of Zoology 64:1675-1678.

Gosselin, L. A., and P. Qian. 1997. Juvenile mortality in benthic marine invertebrates. Marine Ecology Progress Series 146: 265-282.

Hixon, M. A., and W. N. Brostoff. 1983. Damselfish as keystone species in reverse: intermediate disturbance and diversity of reef algae. Science 220:511-513.

Hoey, A., and M. I. McCormick. 2004. Selective predation for low body condition at the larval-juvenile transition of a coral reef fish. Oecologia 139:23-29.

Hoey, A. S., and M. I. McCormick. 2006. Effects of subcutaneous fluorescent tags on the growth and survival of a newly settled coral reef fish, Pomacentrus amboinensis (Pomacentridae). Proceedings of the 10th International Coral Reefs Symposium 1:420-425.

Holmes, T. H., and M. I. McCormick. 2006. Location influences size-selective predation on newly-settled reef fish. Marine Ecology Progress Series 317:203-209.

Jones, G. P. 1991. Post-recruitment processes in the ecology of coral reef fish populations: a multifactorial perspective. Pages 294-328 in P. F. Sale, editor. The ecology of fishes on coral reefs. Academic Press, New York, New York, USA.

Jones, M. E., and P. H. Barber. 2005. Characterization of microsatellite loci for the detection of temporal genetic shifts within a single cohort of the brown demoiselle, Neopomacentrus filamentosus. Molecular Ecology Notes 5:834-836.

Kent, A., S. J. Hawkins, and C. P. Doncaster. 2003. Population consequences of mutual attraction between settling and adult barnacles. Journal of Animal Ecology 72:941-952.

Kerrigan, B. A. 1996. Temporal patterns in the size and condition of settlement in two tropical reef fishes (Pomacentridae: Pomacentrus amboinensis and $P$. nagasakiensis). Marine Ecology Progress Series 135:27-41.

Krause, J., and G. D. Ruxton. 2002. Living in groups. Oxford University Press, New York, New York, USA.

Lecchini, D., J. S. Shima, B. Banaigs, and R. Galzin. 2005. Larval sensory abilities and mechanisms of habitat selection of a coral reef fish during settlement. Oecologia 143:326-334.

Martin, J. 1994. Predation on juvenile coral reef fish at Lizard Island, northern Great Barrier Reef: an ecological and behavioural study. Bachelor of Science honours thesis, James Cook University, Townsville, Australia.

McCormick, M. I. 1990. Handbook for stock assessment of agar seaweed Pterocladia lucida - with a comparison of survey techniques. NZ Fisheries Technical Report 24:1-36.

McCormick, M. I. 2006. Mothers matter: crowded reefs lead to stressed mothers and smaller offspring in marine fish. Ecology 87:1104-1109.

McCormick, M. I., and A. S. Hoey. 2004. Larval growth history determines juvenile growth and survival in a tropical marine fish. Oikos 106:225-242.

McCormick, M. I., and L. J. Makey. 1997. Post-settlement transition in coral reef fishes: overlooked complexity in niche shifts. Marine Ecology Progress Series 153:247-257.

McCormick, M. I., L. Makey, and V. Dufour. 2002. Comparative study of metamorphosis in tropical reef fishes. Marine Biology 141:841-853.

Meekan, M. G., S. G. Wilson, A. Halford, and A. Retzel. 2001. A comparison of catches of fishes and invertebrates by two light trap designs, in tropical NW Australia. Marine Biology 139:373-381.

Menge, B. A. 1995. Indirect effects in marine rocky intertidal interaction webs: patterns and importance. Ecological Monographs 65:21-74.

Michael, S. W. 2004. Basslets, dottybacks and hawkfishes. T. F. H. Publications, Neptune City, New Jersey, USA.

Moland, E., J. V. Eagle, and G. P. Jones. 2005. Ecology and evolution of mimicry in coral reef fishes. Oceanography and Marine Biology: an Annual Review 43:455-482.
Morgan, M. J., and P. W. Colgan. 1987. The effects of predator presence and shoal size on foraging in bluntnose minnows, Pimephales notatus. Environmental Biology of Fishes 20:105111.

Nanami, A., and M. Nishihira. 2003. Population dynamics and spatial distribution of coral reef fishes: comparison between continuous and isolated habitats. Environmental Biology of Fishes 68:101-112.

Ohgushi, T. 2005. Indirect interaction webs: herbivore-induced effects through trait change in plants. Annual Review of Ecology Evolution and Systematics 36:81-105.

Öhman, M. C., P. L. Munday, G. P. Jones, and M. J. Caley. 1998. Settlement strategies and distribution patterns of coralreef fishes. Journal of Experimental Marine Biology and Ecology 225:219-238.

Paradis, A. R., P. Pepin, and J. A. Brown. 1996. Vulnerability of fish eggs and larvae to predation: review of the influence of the relative size of prey and predator. Canadian Journal of Fisheries and Aquatic Sciences 53:1226-1235.

Pechenik, J. A., D. E. Wendt, and J. N. Jarrett. 1998. Metamorphosis is not a new beginning. Larval experience influences juvenile performance. BioScience 48:901-910.

Planes, S., and P. Romans. 2004. Evidence of genetic selection for growth in new recruits of a marine fish. Molecular Ecology 13:2049-2060.

Rice, J. A., L. B. Crowder, and E. A. Marschall. 1997. Predation on juvenile fishes: dynamic interactions between size-structured predators and prey. Pages $333-356$ in R. C. Chambers and E. A. Trippel, editors. Early life history and recruitment in fish populations. Chapman and Hall, New York, New York, USA.

Sale, P. F. 1975. Patterns of use of space in a guild of territorial reef fishes. Marine Biology 29:89-97.

Schmitz, O. J. 1998. Direct and indirect effects of predation and predation risk in old-field interaction webs. American Naturalist 51:327-342.

Searcy, S. P., and S. Sponaugle. 2001. Selective mortality during the larval-juvenile transition in two coral reef fishes. Ecology 82:2452-2470.

Shulman, M. J. 1985. Recruitment of coral reef fishes: effects of distribution of predators and shelter. Ecology 66:1056-1066.

Shulman, M. J., J. C. Ogden, W. N. McFarland, S. L. Miller, N. G. Wolf, and J. P. Ebersole. 1983. Priority effects in the recruitment of juvenile coral reef fishes. Ecology 64:1508 1513.

Sogard, S. M. 1997. Size-selective mortality in the juvenile stage of teleost fishes: a review. Bulletin of Marine Science 60: $1129-1157$.

Stachowicz, J. J. 2001. Mutualism, facilitation, and the structure of ecological communities. BioScience 51:235-246.

Sweatman, H. P. A. 1983. Influence of conspecifics on choice of settlement sites by larvae of two pomacentrid fishes (Dascyllus aruanus and D. reticulatus) on coral reefs. Marine Biology 75:225-229.

Sweatman, H. 1988. Field evidence that settling coral reef fish larvae detect resident fishes using dissolved chemical cues. Journal of Experimental Marine Biology and Ecology 124: $163-174$.

Vigliola, L., and M. G. Meekan. 2002. Size at hatching and planktonic growth determine post-settlement survivorship of a coral reef fish. Oecologia 131:89-93.

Vonesh, J. R. 2005. Sequential predator effects across three life stages of the African tree frog, Hyperolius spinigularis. Oecologia 143:280-290.

Webster, M. S., and G. R. Almany. 2002. Positive indirect effects in a coral reef fish community. Ecology Letters 5:549 557.

Zeller, D. C. 1988. Short-term effects of territoriality of a tropical damselfish and experimental exclusion of large fishes on invertebrates in algal turfs. Marine Ecology Progress Series 44:85-93. 